\title{
Association of MDR1 G2677T polymorphism and leukemia risk: evidence from a meta-analysis
}

\author{
Yulan Yan • Hongjie Liang $\cdot \mathrm{Li} \mathrm{Xie} \cdot$ Yu He $\cdot$ Meng Li • \\ Ruolin Li • Shan Li • Xue Qin
}

Received: 4 September 2013 / Accepted: 2 October 2013/Published online: 20 October 2013

(C) The Author(s) 2013. This article is published with open access at Springerlink.com

\begin{abstract}
In the light of the relationship between the MDR1 G2677T polymorphism and the risk of leukemia remains inclusive or controversial. For better understanding of the effect of MDR1 G2677T polymorphism on leukemia risk, we performed a meta-analysis. Eligible studies were identified through a search of electronic databases such as PubMed, Excerpta Medica Database (Embase), Cochrane Library, and Chinese Biomedical Literature Database (CBM). The association between the MDR1 G2677T polymorphism and leukemia risk was conducted by odds ratios (ORs) and $95 \%$ confidence intervals $(95 \% \mathrm{CI})$. A total of seven publications including eight studies with 1,229 cases and 1,097 controls were included in the meta-analysis. There was no association between MDR1 G2677T polymorphism and leukemia risk in all of five models in overall populations ( $\mathrm{T}$ vs. $\mathrm{G}$ : $\mathrm{OR}=1.00$,
\end{abstract}

\author{
Yulan Yan and Hongiie Liang contributed equally to this work \\ Y. Yan $\cdot$ H. Liang $\cdot$ L. Xie $\cdot$ Y. He $\cdot$ M. Li $\cdot$ R. Li $\cdot$ S. Li $(\bowtie) \cdot$ \\ X. Qin $(\triangle)$ \\ Department of Clinical Laboratory, First Affiliated Hospital of \\ Guangxi Medical University, 6 Shuangyong Road, Nanning 530021, \\ People's Republic of China \\ e-mail: panyan1002@163.com \\ e-mail: xijunshi56234@163.com \\ Y. Yan \\ e-mail: xueying201120521@163.com \\ H. Liang \\ e-mail: lianghongjie2004@163.com \\ L. Xie \\ e-mail: 715085562@qq.com \\ Y. He \\ e-mail: 41918940@qq.com \\ M. Li \\ e-mail: 1825725213@qq.com \\ R. Li \\ e-mail: 2609025345@qq.com
}

$95 \% \mathrm{CI}=0.88-1.12, P=0.914$; TT vs. $\mathrm{GG}: \mathrm{OR}=0.97,95 \%$ $\mathrm{CI}=0.75-1.26, P=0.812$; $\mathrm{TG}$ vs. $\mathrm{GG}: \mathrm{OR}=1.00,95 \% \mathrm{CI}=$ 0.92-1.08, $P=0.939$; TT vs. TG/GG: $\mathrm{OR}=0.98,95 \% \mathrm{CI}=$ 0.67-1.43, $P=0.906$; TT/TG vs. GG: $\mathrm{OR}=1.00,95 \% \mathrm{CI}=$ $0.95-1.06, P=0.994)$. However, the significant association was found in others (Table 2) under the homozygote model (TT vs. GG: $\mathrm{OR}=0.68,95 \% \mathrm{CI}=0.48-0.94, P=0.020$ ) and recessive model (TT vs. TG/GG: $\mathrm{OR}=0.63,95 \% \mathrm{CI}=0.43-$ $0.92, P=0.016)$. In the subgroup analysis, according to the type of leukemia, significant association was found between MDR1 G2677T polymorphism and myeloid leukemia but not lymphoblastic leukemia (TT vs. GG: $\mathrm{OR}=0.66,95 \% \mathrm{CI}=$ $0.46-0.95, P=0.026$; TT vs. TG/GG: $\mathrm{OR}=0.56,95 \% \mathrm{CI}=$ $0.38-0.84, P=0.005)$. The results suggested that there was no association between MDR1 G2677T polymorphism and leukemia risk in overall populations, but significant association was found in others populations (Asians and Africans), and myeloid leukemia indicated that G2677T polymorphism might be a protective factor in the susceptibility of myeloid leukemia and in Asians and Africans.

Keywords MDR1 · Polymorphism · Leukemia · Meta-analysis

\section{Introduction}

Leukemia is a type of malignant clonal hematopoietic stem cell disorder with a bad prognosis due to a range of complicated features, the clonal proliferation of leukemia cells because of uncontrolled differentiation disorder, disruption and other mechanisms of apoptosis in the bone marrow, and other hematopoietic tissues proliferate accumulation and infiltration of other tissues and organs with inhibition of normal hematopoiesis [1]. Leukemia was divided into acute leukemia and chronic leukemia, according to the speed of onset, while acute 
leukemia can also be subdivided into acute lymphoid leukemia (ALL) and acute myeloid leukemia (AML), according to cytogenic analysis [2]. ALL is more common in children, which comprises over $80 \%$ of all acute leukemia. It is estimated that approximately 33.6 in every $1,000,000$ children under 15 years old will develop ALL. However, the etiology of pediatric ALL remains poorly understood; genetic and familial factors were proved as risk factors for leukemia [3-5], while AML is the most common form of acute leukemia in adults as well as in children [6]. It is an extremely heterogeneous malignant disease resulting from acquired mutations that block the differentiation of primitive hematopoietic cells, accordingly causing immature myeloid precursors to accumulate, and resulting in an estimated 13,330 cases and an estimated 8,950 deaths in the USA in 2010 [7]. The management of AML remains a challenge for hematologists nowadays $[7,8]$. But unfortunately, the exact pathological mechanism of leukemia is still unclear recently. Previous studies suggested that a lot of factors were associated with the susceptibility of leukemia [9-11], and genetic factors have become the focus of researches $[12,13]$.

The multidrug resistance gene (MDR1 or $A B C B 1$ ), located at $7 \mathrm{q} 21.1$, its cDNA spans about $4.5 \mathrm{~kb}$, with a core promoter region and 29 exons ranging in size from 49 to $587 \mathrm{bp}$, and the coding region account for less than $5 \%$ of the total [14]. The MDR1 encodes the membrane transport protein Pglycoprotein (P-gp), an efflux pump that regulates the exit and entry of various substrates from the cell. P-gp is expressed in the intestinal epithelium and affects the disposition and response of many drugs $[15,16]$. At least 50 singlenucleotide polymorphisms (SNPs) in human MDRl gene locus have been reported [14]. The G2677T is the most common variants in the coding region of MDR1 [17]. The polymorphism of G2677T was significantly associated with increased or decreased plasma concentration of P-gp substrates $[18,19]$. There were some reports showed that individuals who had the 2677 TT genotype had lower P-gp messenger RNA expression than those who had 2677 GG genotype [20], while other studies reported an opposite effect of the 2677T mutant allele, namely an increase in transport activity compared with that of $2677 \mathrm{G}$ allele [21], but Tanabe et al. [22] reported a nonsignificant opposite trend for P-gp expression in the placenta in relation to the G2677T polymorphism. These contradictions might be due to the presence of different amino acids at position 893, which might have different effects on different drugs [23]. So, the G2677T polymorphism in MDR gene is one of the important problems in the treatment for cancer patients with chemotherapy, including leukemia [24]. Many studies have shown the association between MDRI G2677T polymorphism and the risk of leukemia, but the results remain inconsistent [25-31]. No prior meta-analysis is about MDR1 G2677T polymorphism and leukemia susceptibility. In order to derive a more precise estimation of the association between MDR1 G2677T polymorphism and the risk of leukemia, we carried out this meta-analysis.

\section{Materials and methods}

\section{Search strategy}

Several electronic databases such as PubMed, Excerpta Medica Database (Embase), Cochrane Library, and Chinese Biomedical Literature Database (CBM) are conducted to search eligible studies about the association of MDR1 G2677T polymorphism and leukemia risk before July 2013 by using the keywords "multidrug resistance gene" or "MDR1" or " $A B C B 1$ " or "rs2032582" in combination with "polymorphism" or "variation" and "leukemia" or "leukocythemia" or "leucocythemia." There were no limitations to the language of publication. The reference lists were hand-searched to find more relevant publications.

\section{Inclusion and exclusion criteria}

The following criteria were used to select the eligible studies: (a) a case-control study or studies evaluating the association between the MDR1 G2677T polymorphism and risk of leukemia and (b) the article had to provide sufficient data to estimate an odds ratio (OR) and $95 \%$ confidence interval $(95 \% \mathrm{CI})$. The following exclusion criteria were used for excluding studies: (a) studies contained duplicate data, (b) control population including patients, and (c) case reports or reviews.

\section{Data extraction}

All the data were carefully extracted by the two authors independently from each publication, according to the inclusion and exclusion criteria listed above. If they encountered conflicting evaluations, an agreement was reached following a discussion; if they could not reached to an agreement, a third author was consulted to resolve the debate. The following information were extracted: name of the first author, year of publication, country of origin, ethnicity of the population, genotyping methods, the Hardy-Weinberg equilibrium (HWE) of control, type of leukemia, source of the control group, and the sample size of cases and controls. Different ethnicities were categorized as Caucasians and Mixed and Others, and different leukemia types were categorized as myeloid leukemia (ML) and lymphoblastic leukemia (LL).

Statistical analysis

The strength of the association between MDR1 G2677T polymorphism and leukemia risk was evaluated by pooled OR with $95 \% \mathrm{CI}$ and calculated to assess according to allele 
contrast (T vs. G), homozygote (TT vs. GG), heterozygote (TG vs. GG), recessive (TT vs. TG/GG), and dominant (TT/ TG vs. GG) models. The significance of the summary OR was determined with a $Z$ test and $P<0.05$ was considered as statistically significant. The between-study heterogeneity was assessed by using a chi-square-based $Q$ statistic test. If the result of the heterogeneity test was $P<0.10$, it suggests that between-study heterogeneity existed, and ORs were pooled by random-effects model (DerSimonian and Laird method) [32]. Otherwise, the fixed-effects model (the Mantel-Haenszel method) was used [33]. Moreover, we also used $I^{2}$ value to test the effect of heterogeneity [34]. If obvious heterogeneity existed $\left(I^{2}\right.$ value $>50 \%$ or $\left.P<0.10\right)$, the overall estimate of risk was calculated by the random-effects model; if obvious heterogeneity was absent $\left(I^{2}\right.$ value $<50 \%$ or $P>$ $0.10)$, then the fixed-effects model was used.

The HWE of controls was tested by using a professional web-based program (http://ihg2.helmholtz-muenchen.de/ cgibin/hw/hwa1.pl), $P>0.05$ suggests that the controls followed HWE balance [35]. Studies with the controls not in HWE balance were subjected to sensitivity analysis [36]. Sensitivity analysis was used to test the stability of pooled studies by sequential omission of individual studies. Potential publication bias was estimated by Egger's test $(P<0.05$ was considered representative of statistically significant publication bias) [37] and visual observation of funnel plot [38]. All statistical tests were performed using STATA version 9.2 (STATA Corporation, College Station, TX), using twosided $P$ values.

\section{Results}

\section{Characteristics of studies}

According to the inclusion criteria defined above, a total of seven publications including eight studies with 1,229 cases and 1,097 controls were included in the meta-analysis [25-31]. The flowchart of the selection of studies for inclusion in the meta-analysis is shown in Fig. 1d. The study characteristics included in the meta-analysis were presented in Table 1. These studies were published between 2005 and 2013. All publications were written in English, except for one study in Chinese. Eight independent studies consisted of four Caucasian, two Mix, and two Others (one Asian and one African) populations. The genotype distributions in the controls of all the studies included in the meta-analysis were consistent with HWE (all $P>0.05$ ).

Quantitative synthesis of data

Table 2 listed the main results of the meta-analysis of MDR 1 G2677T polymorphism and leukemia risk. There was no association between MDR1 G2677T polymorphism and leukemia risk in all of the five models in overall population ( $\mathrm{T}$ vs. $\mathrm{G}: \mathrm{OR}=1.00,95 \% \mathrm{CI}=0.88-1.12, P=0.914$; TT vs. $\mathrm{GG}$ : $\mathrm{OR}=0.97,95 \% \mathrm{CI}=0.75-1.26, P=0.812 ; \mathrm{TG}$ vs. $\mathrm{GG}$ : $\mathrm{OR}=1.00,95 \% \mathrm{CI}=0.92-1.08, P=0.939 ;$ TT vs. TG/GG: $\mathrm{OR}=0.98,95 \% \mathrm{CI}=0.67-1.43, P=0.906$, Fig. $1 \mathrm{a} ; \mathrm{TT} / \mathrm{TG}$ vs. GG: $\mathrm{OR}=1.00,95 \% \mathrm{CI}=0.95-1.06, P=0.994)$.

In the subgroup analysis, according to ethnicity, the results suggested that MDR1 G2677T polymorphism was not associated with leukemia risk in Caucasians and Mix population (Table 2). However, significant association was found in Others (Table 2) under the homozygote model (TT vs. GG: $\mathrm{OR}=0.68,95 \% \mathrm{CI}=0.48-0.94, P=0.020)$ and recessive model (TT vs. TG/GG: OR=0.63, $95 \% \mathrm{CI}=0.43-0.92, P=$ 0.016; Fig. 1c) (Table 2). Because the Others only included one study that was about Asian and one was about African, respectively, due to the small sample size, the results are not representatively significant. In the subgroup analysis, according to type of leukemia, significant association was found between MDR1 G2677T polymorphism and ML but not LL (TT vs. GG: $\mathrm{OR}=0.66,95 \% \mathrm{CI}=0.46-0.95, P=0.026$, Fig. 1b; TT vs. TG/GG: $\mathrm{OR}=0.56,95 \% \mathrm{CI}=0.38-0.84, P=$ $0.005)$.

Heterogeneity analysis and sensitive analysis

As shown in Table 2, there was significance between-study heterogeneity in the overall population. Therefore, the random-effect model was utilized to evaluate the relationship of MDR1 G2677T polymorphism with leukemia risk. There was substantial heterogeneity among these studies in overall comparisons. Therefore, we assessed the source of heterogeneity by ethnicity and leukemia type, but the heterogeneity still exists. Sensitivity analysis was used to evaluate the stability of the overall results by sequentially removing individual studies. In our meta-analysis, the result of sensitive analysis shows that no single study could influence the overall results qualitatively, indicating robustness and reliability of our results.

Publication bias

Both Begg's funnel plot and Egger's test were performed to assess the publication bias. The shape of the funnel plot did not suggest any evidence of obvious asymmetry. Similarly, the results revealed the absence of publication bias (data not shown).

\section{Discussion}

In the present study, to clarify controversial results from previous reports, we collected all available published studies and 


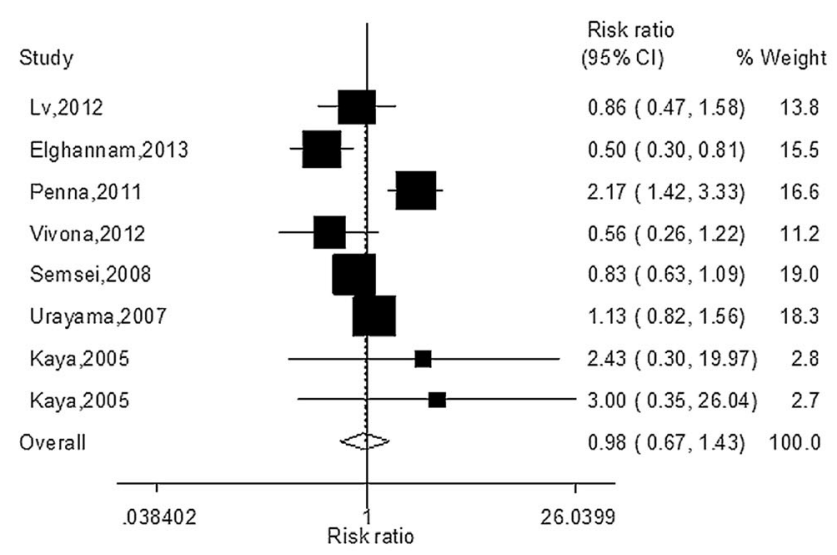

a

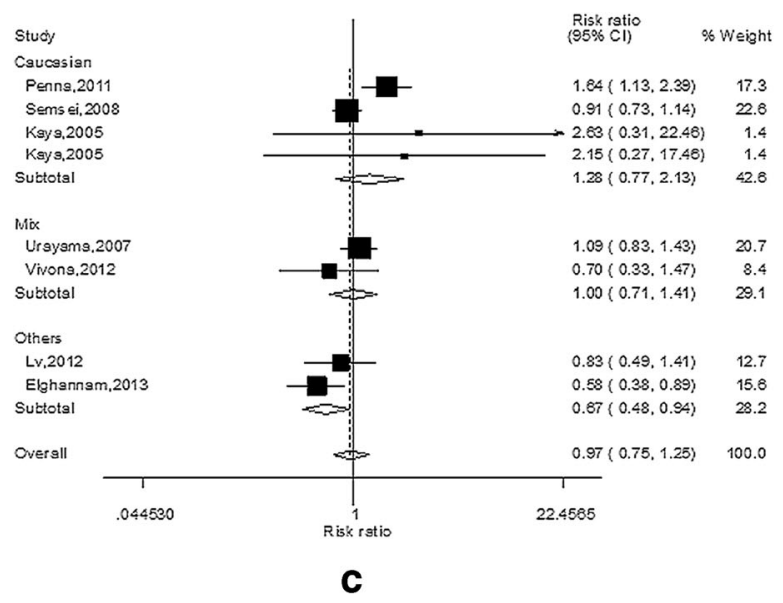

Fig. 1 a The forest plot describing the meta-analysis under recessive model for the association between MDR1 G2677T polymorphism and leukemia risk in overall population (TT vs. TG $+\mathrm{GG}$ ). b The forest plot describing the meta-analysis subgroup analysis base on type of leukemia under recessive model for the association between MDR1 G2677T

performed a meta-analysis to examine the association of MDR1 G2677T polymorphism with susceptibility to leukemia. Our meta-analysis showed that no association was found in all

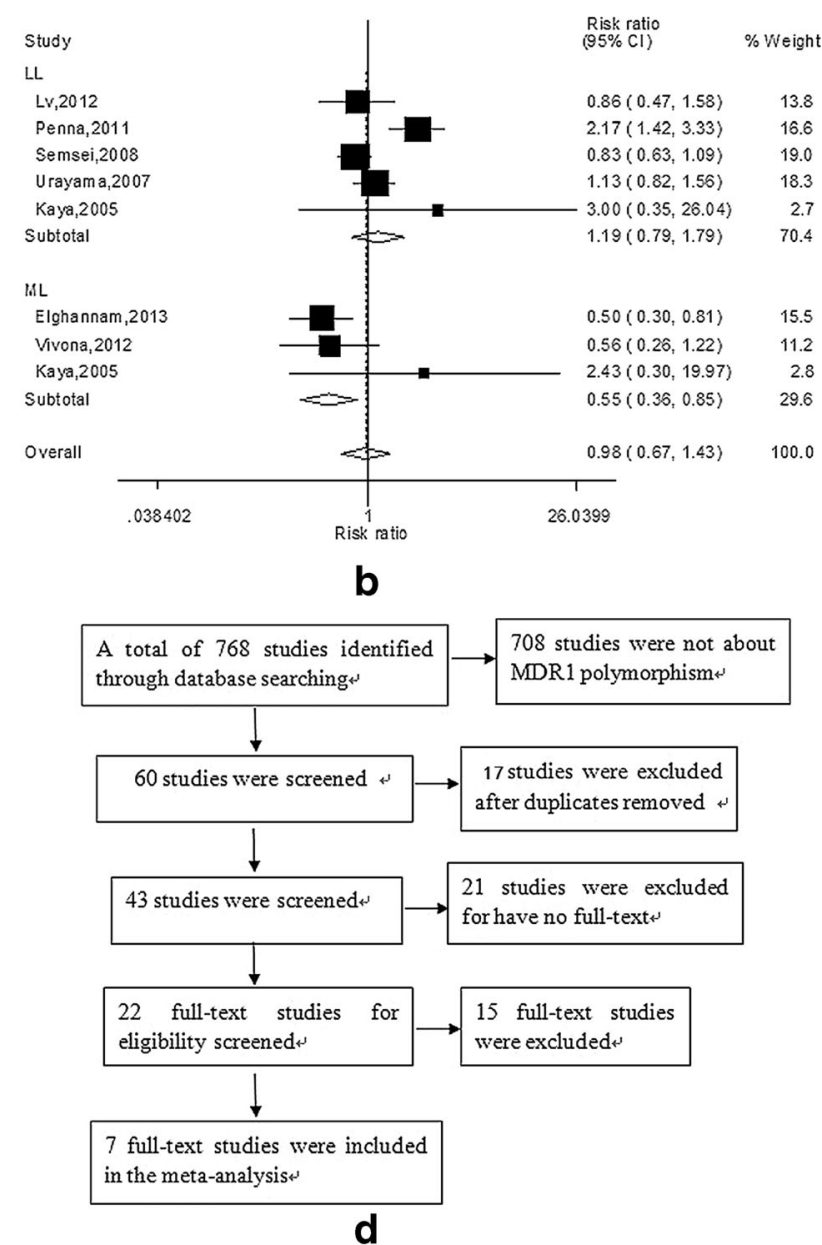

polymorphism and leukemia risk (TT vs. TG + GG). c The forest plot describing the meta-analysis subgroup analysis base on ethnicity under the homozygous model for the association between MDR1 G2677T polymorphism and leukemia risk (TT vs. GG). d Flow chart of selection of studies for inclusion in the meta-analysis

variant genotype carriers. Meanwhile, our data also indicated that the G2677T polymorphism might not be a risk factor in the susceptibility of leukemia. But in subgroup analyses, base on

Table 1 General characteristics of studies included in the meta-analysis

\begin{tabular}{|c|c|c|c|c|c|c|c|c|}
\hline First author & Year & Country & Ethnicity & Method of genotyping & HWE of control & Type of leukemia & Source of control & $\begin{array}{l}\text { Sample size } \\
\text { (case/control) }\end{array}$ \\
\hline Lv et al. [25] & 2012 & China & Asian & PCR & 0.11 & LL & HB & $176 / 170$ \\
\hline Elghannam et al. [26] & 2013 & Egypt & African & PCR & 0.28 & ML & $\mathrm{HB}$ & $96 / 90$ \\
\hline Penna et al. [27] & 2011 & Italy & Caucasian & PCR & 0.45 & LL & $\mathrm{HB}$ & $125 / 125$ \\
\hline Vivona et al. [28] & 2012 & Brazil & Mix & PCR-RFLP & 0.10 & ML & $\mathrm{HB}$ & $118 / 120$ \\
\hline Semsei et al. [29] & 2008 & Hungary & Caucasian & PCR & 0.08 & LL & $\mathrm{HB}$ & $375 / 189$ \\
\hline Urayama et al. [30] & 2007 & USA & Mix & PCR & 0.15 & LL & $\mathrm{HB}$ & $294 / 369$ \\
\hline Kaya et al. [31] & 2005 & Turkey & Caucasian & PCR-RFLP & 0.22 & ML & PB & $28 / 17$ \\
\hline Kaya et al. [31] & 2005 & Turkey & Caucasian & PCR-RFLP & 0.22 & LL & PB & $17 / 17$ \\
\hline
\end{tabular}

PCR-RFLP PCR-restriction fragment length polymorphism, $L L$ lymphoblastic leukemia, $M L$ myeloid leukemia, $H B$ hospital based, $P B$ population based 
Table 2 Results of meta-analysis for MDR1 G2677T polymorphism and leukemia risk
$O R$ odds ratio, $C I$ confidence interval, $F$ fixed-effects model, $R$ random-effects model, $M L$ myeloid leukemia, $L L$ Lymphocytic leukemia

\begin{tabular}{|c|c|c|c|c|c|c|c|c|}
\hline \multirow[t]{2}{*}{ Comparison } & \multirow[t]{2}{*}{ Population } & \multirow[t]{2}{*}{$N$} & \multicolumn{3}{|c|}{ Test of association } & \multirow[t]{2}{*}{ Model } & \multicolumn{2}{|c|}{ Test of heterogeneity } \\
\hline & & & OR & $95 \% \mathrm{CI}$ & $P$ & & $P$ & $I^{2}$ \\
\hline \multirow[t]{6}{*}{ T vs. G } & Overall & 8 & 1.00 & $0.88-1.12$ & 0.914 & $\mathrm{R}$ & 0.011 & 61.6 \\
\hline & Caucasians & 4 & 1.13 & $0.87-1.46$ & 0.377 & $\mathrm{R}$ & 0.029 & 66.7 \\
\hline & Mix & 2 & 1.03 & $0.92-1.15$ & 0.647 & $\mathrm{~F}$ & 0.826 & 0 \\
\hline & Others & 2 & 0.83 & $0.67-1.03$ & 0.099 & $\mathrm{R}$ & 0.139 & 54.4 \\
\hline & ML & 3 & 0.86 & $0.73-1.02$ & 0.075 & $\mathrm{~F}$ & 0.168 & 43.9 \\
\hline & LL & 5 & 1.04 & $0.92-1.19$ & 0.510 & $\mathrm{R}$ & 0.042 & 59.7 \\
\hline \multirow[t]{6}{*}{ TT vs. GG } & Overall & 8 & 0.97 & $0.75-1.26$ & 0.812 & $\mathrm{R}$ & 0.020 & 57.8 \\
\hline & Caucasians & 4 & 1.28 & $0.77-2.13$ & 0.334 & $\mathrm{R}$ & 0.034 & 64.3 \\
\hline & Mix & 2 & 1.01 & $0.78-1.31$ & 0.922 & $\mathrm{~F}$ & 0.268 & 18.6 \\
\hline & Others & 2 & 0.68 & $0.48-0.94$ & 0.020 & $\mathrm{~F}$ & 0.307 & 4.3 \\
\hline & ML & 3 & 0.66 & $0.46-0.95$ & 0.026 & $\mathrm{~F}$ & 0.452 & 0 \\
\hline & LL & 5 & 1.10 & $0.85-1.42$ & 0.491 & $\mathrm{R}$ & 0.070 & 53.9 \\
\hline \multirow[t]{6}{*}{ TG vs. GG } & Overall & 8 & 1.00 & $0.92-1.08$ & 0.939 & $\mathrm{~F}$ & 0.618 & 0 \\
\hline & Caucasians & 4 & 0.97 & $0.784-1.11$ & 0.642 & $\mathrm{~F}$ & 0.433 & 0 \\
\hline & Mix & 2 & 1.05 & $0.93-1.18$ & 0.447 & $\mathrm{~F}$ & 0.162 & 48.9 \\
\hline & Others & 2 & 0.95 & $0.80-1.11$ & 0.496 & $\mathrm{~F}$ & 0.959 & 0 \\
\hline & ML & 3 & 1.08 & $0.88-1.32$ & 0.477 & $\mathrm{~F}$ & 0.250 & 27.9 \\
\hline & LL & 5 & 0.98 & $0.90-1.07$ & 0.635 & $\mathrm{~F}$ & 0.731 & 0 \\
\hline \multirow[t]{6}{*}{ TT vs. TG/GG } & Overall & 8 & 0.98 & $0.67-1.43$ & 0.906 & $\mathrm{R}$ & 0 & 73.9 \\
\hline & Caucasians & 4 & 1.53 & $0.79-3.39$ & 0.291 & $\mathrm{R}$ & 0.001 & 80.6 \\
\hline & Mix & 2 & 0.88 & $0.45-1.69$ & 0.691 & $\mathrm{R}$ & 0.101 & 62.7 \\
\hline & Others & 2 & 0.63 & $0.43-0.92$ & 0.016 & $\mathrm{~F}$ & 0.162 & 48.9 \\
\hline & ML & 3 & 0.56 & $0.38-0.84$ & 0.005 & $\mathrm{~F}$ & 0.350 & 4.7 \\
\hline & LL & 5 & 1.19 & $0.79-1.79$ & 0.411 & $\mathrm{R}$ & 0.004 & 74.1 \\
\hline \multirow[t]{6}{*}{ TT/TG vs. GG } & Overall & 8 & 1.00 & $0.95-1.06$ & 0.994 & $\mathrm{~F}$ & 0.748 & 0 \\
\hline & Caucasians & 4 & 1.02 & $0.93-1.11$ & 0.692 & $\mathrm{~F}$ & 0.904 & 0 \\
\hline & Mix & 2 & 1.03 & $0.94-1.13$ & 0.514 & $\mathrm{~F}$ & 0.415 & 0 \\
\hline & Others & 2 & 0.91 & $0.81-1.03$ & 0.132 & $\mathrm{~F}$ & 0.509 & 0 \\
\hline & ML & 3 & 0.98 & $0.84-1.14$ & 0.792 & $\mathrm{~F}$ & 0.243 & 29.4 \\
\hline & LL & 5 & 1.004 & $0.95-1.07$ & 0.890 & $\mathrm{~F}$ & 0.882 & 0 \\
\hline
\end{tabular}

ethnicity and type of leukemia, significant association was found in Others population and myeloid leukemia (Table 2), which indicated that $\mathrm{G} 2677 \mathrm{~T}$ polymorphism might be a protective factor in the susceptibility of myeloid leukemia in Asians and Africans. Since only one study was about Asian and one about African, taking the small sample size into account, the results are not representatively significant. Conclusions should be interpreted with caution.

Previous studies reported that P-gp as a transmembrane efflux pump for various structurally unrelated anticancer agents and toxins $[14,39]$ and a high expression of P-gp on tumor cells have been shown to correlate with a poor response to chemotherapy and poor prognosis in cancer patients [40]. Many researchers have investigated the effects of the MDRI polymorphisms on the development of drug resistance [41-43]. One of the most important MDR1 gene polymorphisms is G2677T SNP. The polymorphism of G2677T was significantly associated with increased or decreased plasma concentration of P-gp substrates [18, 19]. There were some reports showing that individuals who had the 2677 TT genotype had lower P-gp messenger RNA expression than those who had 2677 GG genotype [20], while other studies reported an opposite effect of the $2677 \mathrm{~T}$ mutant allele, namely an increase in transport activity compared with that of $2677 \mathrm{G}$ allele [21], but Tanabe et al. [22] reported a nonsignificant opposite trend for $\mathrm{P}$-gp expression in the placenta in relation to the G2677T polymorphism. Therefore, the biological role of MDR1 polymorphism in carcinogenesis remains unclear. It is hypothesized that the G2677T may affect the activity of P-gp. Our study shows that 2677TT genotype in MDR1 gene plays a protective role in ML patients. This may explain that 2677TT can lead to a low expression of P-gp on ML cells and increased plasma concentration of P-gp substrates, thus not causing the resistance to drugs in ML patients. 
The heterogeneity plays an important role in a metaanalysis, so finding the source of heterogeneity is very important for the final result of the meta-analysis. Significant heterogeneity was observed in our meta-analysis. We used subgroup analysis to find the sources of heterogeneity. In the subgroup analysis by ethnicity, we found heterogeneity still existed in Caucasians. This may explain that although they have same genetic background, different individuals have different lifestyles and exposed to different risk factors, and the levels of exposure to risk factors also differ; this may cause the heterogeneity. It is possible that other limitations of recruited studies may partially contribute to the observed heterogeneity. For this reason, we conducted analyses using the random-effects model.

Publication bias is another important aspect which may have a negative effect on a meta-analysis. In our metaanalysis, both funnel plot and Egger's test were used to test the publication bias of the included studies. As a result, both the shape of funnel plot and statistical results show no obvious publication bias; this suggests that the publication bias has little effect on the results in our study, and the results of our meta-analysis are relatively stable.

There are remaining some limitations though we conducted comprehensive analysis to show the association between MDR1 G2677T polymorphism and the risk of leukemia. First, the number of studies and the number of samples included in the meta-analysis were relatively small. Second, only published and written in English and Chinese studies were included in this meta-analysis, thus, publication and potential language bias may have occurred, even though it was not found by making use of the statistical test. Third, subgroup analyses according to age, gender, radiation exposure, and other elements have not been performed in the study due to insufficient relevant data available in the primary studies. So, more studies with larger sample size and providing detailed information should be performed to assess the effect of MDR1 G2677T polymorphism on leukemia risk.

In conclusion, our meta-analysis systematically analyzed the association between MDR1 G2677T polymorphism and the risk of leukemia. The results suggested that there was no association between MDR1 G2677T polymorphism and leukemia risk in overall population, but significant association was found in Others population (Asians and Africans) and myeloid leukemia indicated that G2677T polymorphism might be a protective factor in the susceptibility of myeloid leukemia and in Asians and Africans. Considering the limited sample size and ethnicities included in the meta-analysis, further large-scaled and well-designed studies are needed to confirm our results.

Conflicts of interest None
Open Access This article is distributed under the terms of the Creative Commons Attribution License which permits any use, distribution, and reproduction in any medium, provided the original author(s) and the source are credited.

\section{References}

1. Estey EH. Prognostic factors in acute myelogenous leukemia. Leukemia. 2001;15:670-2.

2. Vardiman JW, Thiele J, Arber DA, Brunning RD, Borowitz MJ, Porwit A, et al. The 2008 revision of the World Health Organization (WHO) classification of myeloid neoplasms and acute leukemia: rationale and important changes. Blood. 2009;114:937-51.

3. Remke M, Pfister S, Kox C, Toedt G, Becker N, Benner A, et al. High-resolution genomic profiling of childhood T-ALL reveals frequent copy-number alterations affecting the TGF-beta and PI3KAKT pathways and deletions at $6 \mathrm{q} 15-16.1$ as a genomic marker for unfavorable early treatment response. Blood. 2009;114:1053-62.

4. Du J, Lu C, Cui G, Chen Y, He J. DNA repair gene XRCC1 polymorphisms and susceptibility to childhood acute lymphoblastic leukemia: a meta-analysis. Chin J Cancer Res. 2013;25:405-15.

5. Guo LM, Xi JS, Ma Y, Shao L, Nie CL, Wang GJ. ARID5B gene rs10821936 polymorphism is associated with childhood acute lymphoblastic leukemia: a meta-analysis based on 39,116 subjects. Tumour Biol. 2013doi:10.1007/s13277-013-1097-0.

6. Gamazon ER, Lamba JK, Pounds S, Stark AL, Wheeler HE, Cao X, et al. Comprehensive genetic analysis of cytarabine sensitivity in a cell-based model identifies polymorphisms associated with outcome in AML patients. Blood. 2013;121:4366-76.

7. Wang J, Yang YG, Zhou M, Xu JY, Zhang QG, Zhou RF, et al. Metaanalysis of randomised clinical trials comparing idarubicin + cytarabine with daunorubicin + cytarabine as the induction chemotherapy in patients with newly diagnosed acute myeloid leukaemia. PLoS One. 2013;8:e60699.

8. Jemal A, Siegel R, Xu J, Ward E. Cancer statistics. CA Cancer J Clin. 2010;60:277-300.

9. He YZ, Hu X, Chi XS, Zhang YC, Deng XB, Wei MT, et al. Association between RAD51 gene polymorphism $(-135 \mathrm{G} / \mathrm{C})$ and susceptibility of myelodysplastic syndrome and acute leukemia: evidence based on a meta-analysis. Tumour Biol. 2013. doi:10.1007/ s13277-013-1085-4.

10. Pannucci NL, Li D, Sahay S, Thomas EK, Chen R, Tala I, et al. Loss of the xeroderma pigmentosum group $\mathrm{b}$ protein binding site impairs $\mathrm{p} 210$ BCR/ABL1 leukemogenic activity. Blood Cancer J. 2013;3:e135.

11. Gruhn B, Naumann T, Gruner D, Walther M, Wittig S, Becker S, et al. The expression of histone deacetylase 4 is associated with prednisone poor-response in childhood acute lymphoblastic leukemia. Leuk Res. 2013;37(10):1200-7.

12. Kitamura $\mathrm{T}$, Watanabe-Okochi N, Inoue $\mathrm{D}$, Togami $\mathrm{K}$, Uchida $\mathrm{T}$, Kagiyama Y, et al. Molecular mechanisms underlying leukemic transformation of myelodysplastic syndromes (MDS) and chronic myelogenous leukemia (CML). Rinsho Ketsueki. 2012;53:734-9.

13. Li ZG, Jiao Y, Li WJ, Deng GR, Cui L, Gao C, et al. Hypermethylation of two $\mathrm{CpG}$ sites upstream of CASP8AP2 promoter influences gene expression and treatment outcome in childhood acute lymphoblastic leukemia. Leuk Res. 2013;37(10):128793.

14. Breier A, Barancik M, Sulova Z, Uhrik B. P-glycoprotein-implications of metabolism of neoplastic cells and cancer therapy. Curr Cancer Drug Targets. 2005;5:457-68.

15. Ho GT, Moodie FM, Satsangi J. Multidrug resistance 1 gene (Pglycoprotein 170): an important determinant in gastrointestinal disease? Gut. 2003;52:759-66. 
16. Zintzaras E. Is there evidence to claim or deny association between variants of the multidrug resistance gene (MDR1 or ABCB1) and inflammatory bowel disease? Inflamm Bowel Dis. 2012;18:562-72.

17. Kimchi-Sarfaty C, Oh JM, Kim IW, Sauna ZE, Calcagno AM, Ambudkar SV, et al. A "silent" polymorphism in the MDR1 gene changes substrate specificity. Science. 2007;315:525-8.

18. Gervasini G, Carrillo JA, Garcia M, San Jose C, Cabanillas A, Benitez J. Adenosine triphosphate-binding cassette B1 (ABCB1) (multidrug resistance 1) G2677T/A gene polymorphism is associated with high risk of lung cancer. Cancer. 2006;107:2850-7.

19. Siegsmund M, Brinkmann U, Schaffeler E, Weirich G, Schwab M, Eichelbaum M, et al. Association of the P-glycoprotein transporter MDR1 (C3435T) polymorphism with the susceptibility to renal epithelial tumors. J Am Soc Nephrol. 2002;13:1847-54.

20. Lamba J, Strom S, Venkataramanan R, Thummel KE, Lin YS, Liu W, et al. MDR1 genotype is associated with hepatic cytochrome P450 3A4 basal and induction phenotype. Clin Pharmacol Ther. 2006;79: 325-38.

21. Kurata Y, Ieiri I, Kimura M, Morita T, Irie S, Urae A, et al. Role of human MDR1 gene polymorphism in bioavailability and interaction of digoxin, a substrate of P-glycoprotein. Clin Pharmacol Ther. 2002;72:209-19.

22. Tanabe M, Ieiri I, Nagata N, Inoue K, Ito S, Kanamori Y, et al. Expression of P-glycoprotein in human placenta: relation to genetic polymorphism of the multidrug resistance (MDR)-1 gene. J Pharmacol Exp Ther. 2001;297:1137-43.

23. Dulucq S, Bouchet S, Turcq B, Lippert E, Etienne G, Reiffers J, et al. Multidrug resistance gene (MDR1) polymorphisms are associated with major molecular responses to standard-dose imatinib in chronic myeloid leukemia. Blood. 2008;112:2024-7.

24. Yan Q, Wajapeyee N. Exploiting cellular senescence to treat cancer and circumvent drug resistance. Cancer Biol Ther. 2010;9:166-75.

25. Lv H, Du Z, Wang W, Zhao W, Wang Y, Hu S, et al. Multidrug resistance gene polymorphisms and childhood acute lymphoblastic leukemia correlation. Chin J Pediatr. 2012;50:692-6.

26. Elghannam DM, Ibrahim L, Ebrahim MA, Azmy E, Hakem H. Association of MDR1 gene polymorphism (G2677T) with imatinib response in egyptian chronic myeloid leukemia patients. Hematology. 2013. doi:10.1179/1607845413Y.0000000102.

27. Penna G, Allegra A, Alonci A, Aguennouz M, Garufi A, Cannavo A, et al. MDR-1 polymorphisms (G2677T and C3435T) in b-chronic lymphocytic leukemia: an impact on susceptibility and prognosis. Med Oncol. 2011;28:1549-54.

28. Vivona D, Bueno CT, Lima LT, Hirata RD, Hirata MH, Luchessi AD, et al. ABCB1 haplotype is associated with major molecular response in chronic myeloid leukemia patients treated with standard-dose of imatinib. Blood Cells Mol Dis. 2012;48:132-6.
29. Semsei AF, Erdelyi DJ, Ungvari I, Kamory E, Csokay B, Andrikovics H, et al. Association of some rare haplotypes and genotype combinations in the MDR1 gene with childhood acute lymphoblastic leukaemia. Leuk Res. 2008;32:1214-20.

30. Urayama KY, Wiencke JK, Buffler PA, Chokkalingam AP, Metayer $\mathrm{C}$, Wiemels JL. MDR1 gene variants, indoor insecticide exposure, and the risk of childhood acute lymphoblastic leukemia. Cancer Epidemiol Biomarkers Prev. 2007;16:1172-7.

31. Kaya P, Gunduz U, Arpaci F, Ural AU, Guran S. Identification of polymorphisms on the MDR1 gene among turkish population and their effects on multidrug resistance in acute leukemia patients. Am J Hematol. 2005;80:26-34.

32. DerSimonian R, Laird N. Meta-analysis in clinical trials. Control Clin Trials. 1986;7:177-88.

33. Mantel N, Haenszel W. Statistical aspects of the analysis of data from retrospective studies of disease. J Natl Cancer Inst. 1959;22:719-48.

34. Higgins JP, Thompson SG. Quantifying heterogeneity in a metaanalysis. Stat Med. 2002;21:1539-58.

35. Zintzaras E. Variance estimation of allele-based odds ratio in the absence of Hardy-Weinberg equilibrium. Eur J Epidemiol. 2008;23:323-6.

36. Zintzaras E, Lau J. Synthesis of genetic association studies for pertinent gene-disease associations requires appropriate methodological and statistical approaches. J Clin Epidemiol. 2008;61:634-45.

37. Egger M, Davey Smith G, Schneider M, Minder C. Bias in metaanalysis detected by a simple, graphical test. BMJ. 1997;315:629-34.

38. Begg CB, Mazumdar M. Operating characteristics of a rank correlation test for publication bias. Biometrics. 1994;50:1088-101.

39. Yuan H, Li X, Wu J, Li J, Qu X, Xu W, et al. Strategies to overcome or circumvent P-glycoprotein mediated multidrug resistance. Curr Med Chem. 2008;15:470-6.

40. Ohsawa M, Ikura Y, Fukushima H, Shirai N, Sugama Y, Suekane T, et al. Immunohistochemical expression of multidrug resistance proteins as a predictor of poor response to chemotherapy and prognosis in patients with nodal diffuse large b-cell lymphoma. Oncology. 2005;68:422-31.

41. Cizmarikova M, Wagnerova M, Schonova L, Habalova V, Kohut A, Linkova A, et al. Mdr1 (c3435t) polymorphism: relation to the risk of breast cancer and therapeutic outcome. Pharmacogenomics J. 2010;10:62-9.

42. George J, Dharanipragada K, Krishnamachari S, Chandrasekaran A, Sam SS, Sunder E. A single-nucleotide polymorphism in the mdr1 gene as a predictor of response to neoadjuvant chemotherapy in breast cancer. Clin Breast Cancer. 2009;9:161-5.

43. Chen S, Huo X, Lin Y, Ban H, Li W, Zhang B, et al. Association of MDR1 and ERCC1 polymorphisms with response and toxicity to cisplatin-based chemotherapy in non-small-cell lung cancer patients. Int J Hyg Environ Health. 2010;213:140-5. 